\title{
Dental Implant Complications-Pharmacological Consideration \& Systemic Conditions
}

\author{
Pranav Patil*, Ajay Chandanwale, Akanksha Patil and Vivek Pakhmode \\ Department of Dentistry, BJ Govt Medical College, India \\ *Corresponding author: Pranav S Patil, Department of Dentistry, BJ Govt Medical College \& Sasoon General Hospital, Pune, Maharastra, India
}

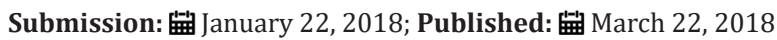

\begin{abstract}
The unique physical, emotional, and developmental characteristics of the person make dental care particularly challenging for the dental implant practitioner. Unfortunately, there is a paucity of literature concerning the use of pharmacologic agents in implant dentistry. This has been attributed largely to the fears and difficulties associated with working with systemic disorder patients. In the literature available, comparison of studies and compilation of information are frequently impossible because of differences in selection criteria, study population, and drug regimens used. Practitioners should use only those drugs in which they have been well trained to avoid excessive risk to the patients. This review aims on the various pharmacological considerations for treating the implant patients with systemic conditions.
\end{abstract}

Keywords: Corticosteroids; Bisphosphonates; Anticoagulants; Antibiotics; Diabetes; Smoking; Immunodeficiency; Cancer therapy

\section{Introduction}

The replacement of missing teeth with endosseous implants for the rehabilitation of edentulous or partially edentulous patients has become a standard of care in the past two decades. This significant progress is based on the concept of osseointegration, first described by the two research groups of Branemark and Schroeder [1,2]. Fundamental experimental studies demonstrated that titanium implants regularly heal with direct bone-to-implant contact, a process termed osseointegration [1] or functional ankylosis [2]. Systemic diseases may affect oral tissues by increasing their susceptibility to other diseases or by interfering with healing. In addition, systemic conditions may be treated with medications or other therapies that potentially affect implants and the tissues carrying them. The first rule is to be critical in case selection. However, some cases yield unexpected outcomes (both good and bad) despite thorough planning and execution of the treatment model. Sometimes the cases start to fail even before the surgeon is aware of it. Understanding medical conditions and pharmacological implication and interaction is critical for any implant surgeon, and this knowledge needs continuous updating. Every surgery performed, every flap raised, every implant placed, every graft done, and every case restored has to be planned and performed to make it successful and safe for the patient.

\section{Pharmacologic Considerations}

\section{Corticosteroids}

Corticosteroids are a common treatment for various systemic diseases. Their use often leads to suppression of a patient's immune response and makes them more prone to developing bacterial, viral, and fungal infections. These infections can be difficult to treat with conventional therapy and patients taking exogenous steroids are at risk for osteopenia and osteoporosis. The clinician should be aware of this when observing the maxilla and mandible [3-6].

\section{Bisphosphonates}

Bisphosphonates are an established category of drugs that function as bone resorption inhibitors by depressing osteoclast function. The efficacy of these agents in treating and preventing the significant skeletal complications associated with these conditions has had a major positive impact for patients and is responsible for their widespread use in medicine. Despite these benefits, osteonecrosis of the jaws has recently emerged as a significant complication in a subset of patients receiving these drugs [7]. Oral bisphosphonates are used frequently to treat osteoporosis and osteopenia, and include alendronate (Fosimax), etidronate (Didronel), residronate (Actonel), and tiludronate (Skelid) [8]. Patients under treatment with oral bisphosphonate therapy are at a considerably lower risk for osteonecrosis of the jaw than patients treated intravenously $[9,10]$. However, given the number of patients on oral bisphosphonate therapy, it is likely that at some point, practitioners will encounter patients with osteonecrosis of the jaw. More studies need to be conducted to determine accurately the incidence of this disease in the population and to assess the risk associated with long-term use of the drugs [11]. A patient is considered to have bisphosphonate related osteonecrosis of the jaw if they have the following three characteristics: 


\section{A. Current or previous treatment with a bisphosphonate}

B. Exposed necrotic bone in the maxillofacial region that has persisted for more than 8 weeks

\section{No history of radiation therapy to the jaws}

Management of patients with bisphosphonate-related osteonecrosis is extremely difficult. Surgical debridement has not been effective in eradicating the necrotic bone, and hyperbaric oxygen therapy has not been uniformly effective in limiting the progression of this process. It is difficult to obtain a surgical margin with viable bleeding bone. Therefore, surgical treatment should be avoided in most cases. Areas of necrotic bone that are a constant source of soft tissue irritation should be removed without exposing additional bone. However, it is likely that the margin of the debridement will remain exposed. Symptomatic patients with pathologic mandibular fractures may require a segmental resection with a continuity defect and immediate reconstruction with a rigid plate. Reconstruction of these patients with free or vascularized bone is not feasible given the likelihood that necrotic bone will be present or develop at the resection margin. Most patients with limited areas of exposed bone can be managed with irrigations and antibiotic therapy that is tailored to the culture and sensitivity data. Guidelines for the treatment of dental patients receiving intravenous bisphosphonate treatments should be different than for patients taking the oral formulation of this medication. According to the Grant, oral bisphosphonate treatments did not results in the bisphosphonate associated osteonecrosis of the jaw and also reported that the implant success rate were comparable in patients taking bisphosphonate \& those not receiving oral bisphosphonate.

\section{Anticoagulants}

The three main anticoagulants are coumarin, heparin, and aspirin. They are usually prescribed to treat a number of cardiac or vascular disorders, including atrial fibrillation, ischemic cardiac disease, cardiac valvular disease, prosthetic cardiac valves, post-MI, deep venous thrombosis, pulmonary embolism, cerebrovascular accident, and many others [12-14]. Aspirin use in the USA remains high because of its diverse and beneficial activities. In adults at risk for cardiovascular thrombotic events, low-dose aspirin (81mg/day) is an excellent preventive agent; however, its antiplatelet properties have contributed to a perceived increased risk for bleeding after dental extractions [15].

Combination aspirin and the adenosine diphosphate PSY [16] receptor antagonist, clopidogrel (Plavix), therapy helps prevent thrombotic complications following a percutaneous coronary stent intervention [17]. In contrast, no additional benefit was found for aspirin and clopidogrel compared with aspirin alone to prevent cardiovascular events in patients with athero-thrombotic risk factors [18]. The combination of aspirin and clopidogrel has been associated with bleeding risk with coronary artery bypass graft surgery $[19,20]$. However, no studies have examined whether an increased risk of bleeding exists in the dental setting following extractions compared with more invasive surgical procedures such as coronary artery bypass grafting. Of importance, a recent science advisory from the American Heart Association, American College of Cardiology, Society for Cardiovascular Angiography and Interventions, American College of Surgeons, and the American Dental Association recommended continuing aspirin and clopidogrel therapy for minor dental surgical procedures in patients who have coronary artery stents or delaying treatment until the prescribed antiplatelet regimen is completed, and warned of the significant thrombotic risk of discontinuing therapy [21]. The risk of acute MI is increased during several weeks after cessation of nonsteroidal anti-inflammatory drug therapy. Overall, the data supported the conclusion that among acute coronary syndrome patients, the discontinuance of daily aspirin use increases the risk for adverse clinical cardiovascular outcomes during the first month after drug withdrawal. A slightly different scenario presents with patients who take higher doses of aspirin (i.e. $>1 \mathrm{~g} /$ day) and require dental extractions. These individuals generally take higher doses of aspirin for its analgesic and/or anti-inflammatory properties, and do not have antithrombotic concerns. Therefore, in patients taking aspirin as an analgesic or anti-inflammatory, aspirin use could be discontinued before dental extractions or surgery, as these patients are not at known risk for thrombosis. However, there are several studies $[22,23]$ that indicate that aspirin use can be continued without significant concern for dental bleeding when local hemostatic measures are in place.

\section{Antibiotics}

The administration of antibiotics in preventing infections following surgical procedures is a common procedure in medicine and dentistry, although such prescription is often empirical [24]. The principle of antibiotic prophylaxis before oral surgical procedures, including dental implants, in patients at risk for endocarditis or in those who are severely immune-compromised is well established. Their use in conjunction with implant surgery in healthy patients and its correlation with failure and success rates are still poorly documented in the literature. However, it is widely agreed that total use of antibiotics should be reduced to minimize the emergence of resistant bacterial strains [25].

\section{Age}

Patient age in and of itself has not been shown to affect implant complication rates significantly [26]. Most clinical studies of implant survival and complications show high success rates, although elderly patients may have more difficulty manipulating removable implantsupported prostheses [27]. However, age is definitely associated with the prevalence of systemic conditions that may affect implant success or complication rates. Older patients more commonly suffer from multiple systemic conditions than do younger patients, particularly conditions of a chronic nature such as hypertension, CVD, and osteoporosis, to name a few. For example, the prevalence of type 2 diabetes increases as a given subject population ages [28]. Therefore, an older individual is more likely to have diabetes. If diabetes increases the likelihood of implant complications and if 
the clinician sees a lot of older patients with diabetes, that clinician may diagnose and treat a greater number of implant complications than one who sees mainly younger patients.

Likewise, the effect of risk factors for implant complications may become more obvious as patient ages simply owing to the cumulative effect of the risk factor over time. For example, smoking may increase the risk of implant complications. A person who has accumulated 50 pack-years of smoking exposure may be more likely to exhibit the negative clinical effects of that accumulated risk exposure than a person who only has a 5-pack-year smoking history. Assuming the two individuals began smoking at the same age, the older individual will accumulate greater risk exposure than will the younger person. Hormonal changes occurring with age mainly affect women. Of particular relevance to implant complications is the decreased bone mineral density associated with aging in both males and females. Because bone mineral density decreases more rapidly after menopause, older women are more likely to have osteopenia or osteoporosis than are age-matched men.

Another consideration for patient age is the number and variety of medications taken. Overall, the prevalence of polypharmacy increases dramatically with age $[29,30]$. Medications can certainly result in implant complications, especially as they relate to surgical risk and alterations in wound healing. Many of these will be discussed later in this chapter. For example, older patients with multiple chronic diseases are more likely than younger patients to take medications that increase the risk of intraoperative or postoperative bleeding, postural hypotension, xerostomia and mucosal irritation, gingival enlargement, and immunosuppression. In addition, use of multiple medications increases the risk of drug interactions with medications prescribed by the dentist. Thus, it is not a patient's age per se that determines risk for implant complications, but rather the increased prevalence of systemic conditions that occur with age, the increased level of risk factor exposure, and the medications that are used in managing such conditions.

\section{Diabetes}

Despite its widespread prevalence throughout the world, there is relatively little evidence on diabetes as a direct risk factor for dental implant complications or failure. Diabetes is associated with a wide range of systemic complications including microvascular and macrovascular diseases, altered wound healing, and increased susceptibility to infection [31]. These conditions may increase the risk of postsurgical complications following dental implant placement. In addition, diabetes is a major risk factor for periodontal disease. Dental implants are often used to restore function in partially edentulous patients. In these individuals, the clinician must perform a thorough examination of the remaining dentition and must understand those factors that increase the risk for periodontal destruction, such as diabetes. Further progression of existing periodontitis in such patients may alter the functional load on existing implant supported restorations or may necessitate further implant placement.
Diabetes negatively impacts bone metabolism, with decreased osteoblast differentiation and proliferation, decreased collagen production, and increased osteoblast apoptosis having been demonstrated in hyperglycemic environments [32]. Animal models of type 1 diabetes reveal decreased bone-to-implant contact on machined surface and rough surface dental implants placed in diabetic animals compared with non-diabetic animals [33,34]. Trabecular bone volume around implants is also decreased in diabetic animals. Cortical bone remains relatively unaffected. Conversely, animal models of type 2 diabetes have shown no difference in osseointegration or trabecular bone volume around machined surface implants compared with non-diabetic control animals [35]. If diabetes does negatively affect osseointegration, it is more likely to impact implants placed in regions with a predominance of cancellous bone, such as the maxilla than in regions with an abundance of cortical bone such as the anterior mandible. Interestingly, when insulin is used to establish good glycemic control in diabetic animal models, bone-to-implant contact increases markedly compared with animals with uncontrolled diabetes, suggesting that establishing good glycemic control may be an important determinant of osseointegration [36].

A systematic review of the available evidence in 2007 suggested that diabetes might have a small negative impact on implant survival in humans over time [37]. However, one of the major findings of the review was the paucity of studies examining this important question. Almost all human studies have been limited to individuals with type 2 diabetes, and few have examined the impact of various levels of glycemic control on implant outcomes. Studies of implants in the anterior mandible have shown 5 -year survival rates of 88$94 \%$ in subjects with type 2 diabetes [38,39]. While these studies did not directly compare diabetic and non-diabetic patients, the 88-94\% survival rate is somewhat lower than that seen in other studies of non-diabetic subjects. For example, 5 year survival rates of implants placed in the anterior mandible of non-diabetic subjects have ranged from $98 \%$ to $100 \%[40,41]$. In a large prospective study of over 2600 implants in various anatomic locations of both non-diabetic and type 2 diabetic patients, implant survival rates at least 3 years after placement were $93 \%$ in non-diabetic and $92 \%$ in diabetic individuals [42]. Conversely, in a smaller retrospective study of 215 implants placed in both type 1 and type 2 diabetic patients the cumulative 6-year survival rate was $85.7 \%$ [43].

One of the mostimportant factors in preventing systemic diabetic complications such as retinopathy, nephropathy, and neuropathy is establishing good glycemic control. In general, glycemic control is evaluated clinically through use of the glycosylated hemoglobin assay, or HbAlc. This assay allows the determination of the average glucose levels over the 2-3 months preceding the test. A normal HbAlc is less than 6\%. The American Diabetes Association (ADA) recommends that most people with diabetes try to control their blood glucose levels well enough to maintain an HbA1c below $7 \%$ [44]. There is strong evidence that improved glycemic control decreases the risk of long-term diabetic complications $[45,46]$. However, there is little evidence evaluating the impact of glycemic 
control on dental implant survival or complications in people with diabetes. Very few implant studies have even examined the level of glycemic control in their diabetic patient populations. A recent study examined the question of how glycemic control affects implant complication rates in type 2 diabetic individuals with HbAlc levels ranging from $4.5 \%$ to $13.8 \%$ [47]. All of the implants successfully integrated and were in function at least 1 year after placement. This small study suggests that implants can be placed successfully in diabetic patients with a range of glycemic control.

However, only three subjects had HbAlc levels over $10 \%$ and only short-term survival was evaluated, so clinicians should assess these data carefully. In general, poor glycemic control is considered a risk factor for postsurgical infection. Thus, until more data specifically related to dental implant surgery become available, risks associated with implant therapy should be evaluated carefully in diabetic individuals with poor glycemic control, and detailed informed consent should be obtained.

\section{Smoking}

There is no question that smoking has numerous deleterious effects on tissues and on the host immune-inflammatory response. Products of tobacco such as nicotine, carbon monoxide, and hydrogen cyanide alter wound healing by decreasing proliferation of fibroblasts and other reparative cells, decreasing tissue perfusion through vasoconstriction, and increasing platelet adhesion [48]. Hydrogen cyanide inhibits oxidative metabolism, while carbon monoxide decreases tissue oxygenation by competitive binding to hemoglobin. Smoking up-regulates production of certain proinflammatory cytokines such as interleukin-1 and tumor necrosis factor-a, while also adversely affecting humoral immune responses. Smoking has a deleterious effect on secretory immune functions as well, which may adversely impact healing in the maxillary sinus. Smoking decreases osteoblast activity, resulting in diminished bone mineral density and delayed bone healing after surgery. While these adverse effects of smoking exist and could affect healing following implant placement, the clinical question remains as to the impact of smoking on actual implant survival and the rate of complications. Many studies have examined the impact of smoking on dental implant therapy. Unfortunately, most of these studies do not clearly delineate the degree of smoking exposure such as the number of cigarettes smoked or the duration of smoking. Numerous studies report an increased failure rate of implants in smokers compared with nonsmokers. In general, the failure rate is reported to be 2-2.5 times higher in smokers [49,50]. In some studies, implants placed in the maxilla are negatively affected by smoking to a greater degree than those placed in the mandible, perhaps owing to the generally greater bone density in the mandible. In addition, the implant surface may have a major impact on the effect of smoking on implant outcomes.

Systematic reviews provide clinicians with the highest level of evidence, and several systematic reviews of data related to smoking and implant therapy have been published in the past few years
$[51,52]$. These studies examining data from thousands of implants confirm that overall, implant failure rates are approximately twofold higher in smokers compared with non-smokers. For example, in one systematic review the overall survival rate in smokers was 89.7\% compared with $93.3 \%$ in non-smokers [53]. Looked at another way, the overall failure rate was $10.3 \%$ in smokers, versus $6.7 \%$ in non-smokers. Several major factors need to be considered in interpreting the results of these smoking studies. First, the impact of smoking may vary with the anatomic location in which implants are placed. A large study of over 2500 implants evaluated at least 3 years after placement demonstrated an implant failure rate of $10.9 \%$ for maxillary implants in smokers versus $6.4 \%$ for maxillary implants in non-smokers, a difference of $4.5 \%$ [50]. Conversely, in the mandible the failure rate was $6.9 \%$ for smokers and $5.6 \%$ for non-smokers, a difference of only $1.3 \%$. This study suggests that the impact of smoking may be greater for maxillary implants than for mandibular implants. This concept was confirmed in a large systematic review that found a statistically significant two-fold increased failure rate in maxillary implants in smokers compared with non-smokers, but no significant difference in mandibular implant failure rates [51]. Another systematic review found a $2.0 \%$ overall difference in survival rate for smokers versus non-smokers when implants placed in all anatomic locations were evaluated, but the difference in failure rate was $7.4 \%$ when only maxillary sites were considered [53].

Another special anatomic consideration for smokers is the impact their habit may have on implants placed inaugmented sites such as maxillary sinuses or ridges that have been grafted. Most studies show that implant survival rates in sites that have been previously augmented by bone grafting are similar to sites where implants have been placed in native bone [54-56]. However, smoking may be a major factor in altering the outcome in such sites. A large systematic review concluded that smoking has a particularly strong negative effect on the survival of implants placed in either augmented maxillary sinuses or alveolar ridges. Compared with an overall 2.1-fold increased risk of implant failure in smokers versus nonsmokers, when implants were placed in augmented sites in smokers the failure rate was 3.6-fold higher than for implants placed in augmented sites in non-smokers [52]. Thus, clinicians should anticipate the possibility of higher failure rates for implants placed in bone augmented sites in smokers, and should counsel patients accordingly.

Many implant studies include primarily machined surface implants in their data sets because the studies were initiated at a time when machined surface implants were commonly placed. Smoking adversely affects the survival of machined surface implants to a greater degree than rough surface implants. For example, one systematic review showed a statistically significant 2.25-fold increased failure rate in smokers compared with nonsmokers when implants of all surface types were evaluated [52]. However, when only rough surface implants were evaluated, there was no significant difference in implant survival rates in smokers compared with 
nonsmokers. In another meta-analysis of rough surface dual acid etched implants, the 3-year cumulative survival rate in smokers was $98.7 \%$, almost exactly the same as the $98.4 \%$ survival rate in non-smokers [57]. A large study of sand-blasted and acid-etched implants showed initial short-term implant survival rates of $98 \%$ for both smokers and non-smokers [58]. These results have led many study groups to conclude that rough or micro roughened surface characteristics of dental implants may mitigate the adverse effect of smoking on long-term implant outcomes.

Implant failure is not the only concern of clinicians. Implant complications may also occur, including peri-implantitis, softtissue inflammation, and loss of alveolar bone. Smoking increases the rate of implant complications in most studies that have examined the question. In a systematic review of 13 studies examining peri-implant bone height over time, 11 of the 13 studies found significantly greater bone loss in smokers compared with non-smokers [52]. Again, the negative effect of smoking may be decreased when implants with rough surface characteristics are used. Many of these studies also show an increased rate of periimplant mucosal inflammation, deeper peri-implant probing depths, bleeding, and suppuration in smokers. Even in studies that have shown no difference in implant survival in smokers versus nonsmokers, the rate of soft-tissue complications may be higher in smokers [59]. When an absence of such complications is considered as "success", studies show that the success rate of implants in smokers is significantly lower than in non-smokers. For example, a systematic review found a success rate of $91.0 \%$ for non-smokers, but only $77.0 \%$ for smokers [53].

Over 40 years of research supports the concepts that smokers have a poorer periodontal status overall than non-smokers, that smokers are at greater risk of progressive periodontitis, that smokers are at greater risk of tooth loss, and that smokers do not respond to periodontal therapy as well as non-smokers [48]. Thus, the smoking patient is at increased risk of periodontal destruction which may lead to further loss of teeth and alteration in the function of existing implant-supported restorations. In addition, smoking patients who continue to lose teeth may seek further implant therapy, which may then have a greater risk of failure or complications post-treatment.

\section{Immunodeficiency}

Immunodeficiency can affect a patient's ability to fight infection and can alter wound healing following trauma or surgery. Infection with the human immunodeficiency virus (HIV) results in major changes in immune function. As the disease progresses, the patient may exhibit acquired immunodeficiency syndrome (AIDS)-related signs and symptoms, among which are oral lesions and infections. While advances in therapy over the past 20 years have radically changed survival rates for people with HIV, the disease remains a leading cause of death worldwide [60]. In the USA and other parts of the industrialized world, the use of highly active antiretroviral therapy (HAART) has resulted in decreased mortality rates for
HIV patients. HAART has allowed many people with HIV to live long and productive lives relatively free of medical complications. This means that the dentist is likely to see patients with HIV who desire replacement of missing teeth with dental implant-retained or supported restorations. There is little research on dental implant outcomes in patients with HIV, other than a few case reports and case series which were all published after use of HAART became routine [61-63]. These reports all demonstrate that dental implant survival rates are similar in HIV-positive patients using HAART protocols to those seen in healthy patients. In addition, the rate of postoperative complications in these cases was low, similar to what would be expected in a healthy population. It appears that HIV itself is not a major etiologic factor in implant failure or complications. However, each HIV patient must be evaluated individually, as co morbid conditions such as hepatitis or other viral infections, blood dyscrasias, opportunistic infections, and certain forms of cancer may contraindicate implant therapy.

Immune disorders other than HIV can also alter dental implant therapy. Numerous autoimmune diseases exist that affect oral health and surgical risk. For example, Sjogren's syndrome can result in severe xerostomia leading to rampant caries and tooth extraction. Dry mucosal surfaces are easily irritated by tissueborne prostheses. This may lead a Sjogren's syndrome patient to seek implant-supported restoration. Sjogren's syndrome is not a contraindication to implant therapy, and successful implant treatment has been reported. Successful implant therapy has also been reported for patients with other autoimmune diseases such as scleroderma. In patients with autoimmune conditions, the risk of surgical therapy may be increased, and alterations to the surgical treatment plan may be indicated. For example, patients with systemic lupus erythematosus may have multiple organ involvement and may be at increased risk for bacterial endocarditis due to cardiac valvular damage [64]. Physician consultation may be warranted for patients with these types of autoimmune diseases. Systemic steroids are often used in the management of autoimmune disorders to suppress the immune response. Long-term systemic steroids can induce osteoporosis, which should be considered in the risk-benefit assessment for implant therapy. Systemic steroids may also cause secondary diabetes, which can also affect implant treatment. Immunosuppressant therapy is commonly used in association with organ transplantation, bone marrow transplants, and cancer therapy. There is little evidence available to determine the impact of intentional immunosuppression on implant survival, failure, or complication rates.

\section{Cancer therapy}

Patients with cancer of the head and neck region are often treated with chemotherapy, radiation therapy, or both. These treatments have major negative effects on host defenses and on hematopoiesis. Clearly, a patient undergoing active chemotherapy or radiation therapy is not a candidate for dental implant placement. In general, implant-retained restorations or prostheses show lower long-term survival rates in patients receiving resective head and 
neck cancer therapy than do those in patients without prior cancer treatment [65]. However, it is important to distinguish between patients who have received surgical resection, chemotherapy, radiation therapy, or some combination of treatments. Very little research has been done examining the effect of chemotherapy on implant success and survival rates. The data that are available suggest that a history of chemotherapy before implant placement or a history of chemotherapy after successful integration and restoration of implants has no negative effect on implant survival [66,67]. Radiation treatment has been studied much more extensively than chemotherapy. Radiation therapy has numerous factors that can affect the risk for implant failure or complications [68]. The radiation dose is usually not uniform across the various regions of the jaws. Some areas may receive very high doses while adjacent regions receive little, if any, direct radiation. High-dose radiation markedly decreases vascularity of the bone, a process which continues in the irradiated bone long after treatment. Many patients with oral tumors undergo surgical resection of soft and hard tissues, which can grossly decrease vascularity and can result in limited amounts of remaining bone, often in areas difficult to place dental implants in favorable positions for restoration. Some patients are then reconstructed with bone grafts that may or may not have good vasularization post grafting. All of these factors can increase the failure and complication rates of dental implants.

Systematic reviews of the evidence suggest that implant survival rates are lower in alveolar bone that has been previously irradiated than in non-irradiated bone [69]. Implant failure is relatively low when radiation doses are below $45 \mathrm{~Gy}$. Once above the $45 \mathrm{~Gy}$ level, however, the failure rate does not appear to increase with increasing radiation dose. A systematic review determined a failure rate of $5.4 \%$ at radiation doses of $46-55 \mathrm{~Gy}$, a $5.2 \%$ failure rate at 56-66Gy, and a 5.1\% failure rate at doses above $61 \mathrm{~Gy}$. In this review, the implant failure rate was higher in the irradiated maxilla (17.4\%) than in the irradiated mandible (4.4\%). Most implant failures occur during the first 3 years after placement in previously irradiated bone. No significant differences in implant failure rate were found when radiation was received before implant placement versus after successful implant placement and osseointegration. In examining 19 studies of implant placement in irradiated patients, the overall failure rate was $3.2 \%$ when radiation followed implant placement compared with 5.4\% when radiation preceded implantation [69].

When implants are placed following irradiation, the failure rate may be higher if implants are placed a long time after radiation therapy compared with placement at a shorter time from radiation treatment. In a study of 631 implants in 107 irradiated cancer patients, implant survival decreased significantly when implants were placed longer than 15 years after irradiation [70]. The highest survival rates were seen when implants were placed within 8 years of irradiation. When implants were placed more than 15 years after radiation therapy, the long-term survival rate dropped to less than $50 \%$. Overall, the survival rate was approximately $76 \%$ in this study, again demonstrating that clinicians and radiation patients should expect lower survival rates than had the patient not received radiation. Many irradiated patients have also undergone tumor resection and subsequent bone grafting. In a study of 71 patients treated by resection and radiation therapy with 50Gy of radiation dose, followed by placement of 316 mandibular implants, the implant failure rate after 8 years was $72 \%$ when implants were placed in previously irradiated bone, 95\% when implants were placed in non-irradiated bone, and only $54 \%$ when implants were placed in previously grafted bone [71].

One of the major and potentially devastating oral complications of radiation therapy is osteoradionecrosis (ORN). Hyperbaric oxygen therapy has been widely used to prevent and treat ORN. Hyperbaric oxygen therapy increases tissue vascularity and oxygen tension by promoting angiogenesis. As implants have become more common in irradiated patients, hyperbaric oxygen therapy has been used to attempt to improve implant survival rates and decrease implant complications, one of which is ORN. While some studies have shown improved implant survival rates with hyperbaric oxygen therapy, others have not [72]. A Cochrane review of this issue revealed a paucity of high-quality studies [73]. Unfortunately, only one randomized controlled trial has examined the effect of hyperbaric oxygen on implant survival when compared directly with a control subject group that did not receive hyperbaric oxygen. All implants were placed in the anterior mandible, and five out of 13 patients who received hyperbaric oxygen had at least one implant failure compared with two out of 13 in the non-hyperbaric control group. Overall, there were no significant differences between groups in the number of implant failures. The effect of hyperbaric oxygen therapy on implant outcomes requires more study before a recommendation can be made to include this treatment in clinical protocols.

\section{Conclusion}

In recent years dental implant is the treatment of choice in edentulous patients. Regarding the fact that outcome of this dental implant depends upon the systemic condition of patient, which affects the success of any dental implant therapy. Therefore, proper patient selection, history of any kind of systemic disease or condition and applying the standard rules for the surgical procedure is must for the clinicians. It is better to evaluate the patients overall health before starting the procedure of implant therapy. Consultation, para-clinical and laboratorial test must be done in suspicious cases to obtain definitive long lasting results.

\section{References}

1. Brånemark PI, Adell R, Breine U, Hansson BO, Lindström J, et al. (1969) Intra-osseous anchorage of dental prostheses. I. Experimental studies. Scand J Plast Reconstr Surg 3(2): 81-100.

2. Schroeder A, Pohler O, Sutter F (1976) Tissue reaction to an implant of a titanium hollow cylinder with a titanium surface spray layer. SSO Schweiz Monatsschr Zahnheilkd 86(7): 713-727.

3. Safkan B, Knuuttila M (1984) Corticosteroid therapy and periodontal disease. J Clin Periodontol 11(8): 515-522. 
4. Markitziu A, Zafiropoulos G, Flores JL, Pisanty S (1990) Periodonta alterations in patients with perphigus vulgaris taking steroids. A biannual assessment. J Clin Periodontol 17(4): 228-232.

5. Dubois EF, Roder E, Dekhuijzen PNR, Zwinderman AE, Schweitzer DH (2002) Dual energy X-ray absorptiometry outcomes in male COPD patients after treatment with different flucocorticoid regimens. Chest 121(5): 1456-1463.

6. Heinemann DF (2000) Osteoporosis. An overview of the national osteoporosis foundation clinical practice guide. Geriatrics 55: 31-36.

7. Ruggiero SL, Drew SJ (2007) Osteonecrosis of the jaws and bisphosphonate therapy. J Dent Res 86(11): 1013-1021.

8. Marder M (2004) Medical conditions affecting the success of dental implants. Compend Contin Educ Dent 25(10): 739-742.

9. Ruggiero SI, Mehrotra B, Rosenberg TJ, Engroff SL (2004) Osteonecrosis of the jaws associated with the use of bisphosphonates: a review of 63 cases. J Oral Maxillofac Surg 62(5): 527-534

10. Marx RE, Sawatari Y, Fortin M, Broumand V (2005) Bisphosphonateinduced exposed bone (osteonecrosis/osteopetrosis) of the jaws: risk factors, recognition, prevention and treatment. J Oral Maxillofac Surg 63(11): 1567-1575.

11. AAOMS Position Paper (2007) American association of oral and maxillofacial surgeons position paper on bisphosphonate related osteonecrosis of the jaws. J Oral Maxillofac Surg 65(3): 369-376.

12. Blinder D, Manor Y, Martinowitz U, Taicher S, Haswhomer T (1999) Denta extractions in patients maintained on continued oral anticoagulants: comparison of local hemostatic modalities. Oral Surg Oral Med Oral Pathol Oral Radiol Endod 88(2): 137-140.

13. Little JW, Falace DA, Miller CS, Rhodus NL (1997) Dental management of the medically compromised patient. ( $5^{\text {th }}$ edn), MO: CV Mosby, St Louis, USA.

14. Schardt SD (2000) Update on coagulopathies. Oral Surg Oral Med Ora Pathol Oral Radiol Endod 90(5): 559-563.

15. Brennan M, Wynn R, Miller C (2007) Aspirin and bleeding in dentistry: an update and recommendations. Oral Surg Oral Med Oral Pathol Oral Radiol Endod 104(3): 316-323.

16. Antithrombotic Trialists' Collaboration (2002) Collaborative metaanalysis of randomized trials of antiplatelet therapy for prevention of death, myocardial infarction, and stroke in high risk patients. BMJ 324(7329): 71-86.

17. Steinhubl SR (2006) Optimizing antiplatelet therapy for the ACS patient: reacting to clinical trial data from the ISARREACT- 2 studies. Rev Cardiovasc Med 7(Suppl 4): S12-S19.

18. Bhatt DL (2006) Clopidogrel bisulfate in ST-segment elevation myocardial infarction: a viewpoint by Deepak L Bhatt. Am J Cardiovasc Drugs 6(6): 415-416.

19. Chu MW, Wilson SR, Novick RJ, Stitt LW, Quantz MA (2004) Does clopidogrel increase blood loss following coronary artery bypass surgery? Ann Thorac Surg 78(5): 1536-1541.

20. Leong JY, Baker RA, Shah PJ, Cherian VK, Knight JL (2005) Clopidogrel and bleeding after coronary artery bypass graft surgery. Ann Thorac Surg 80(3): 928-933

21. Grines CL, Bonow RO, Casey DE, Gardner TJ, Lockhart PB, et al. (2007) Prevention of premature discontinuation of dual antiplatelet therapy in patients with coronary artery stents. A science advisory from the American Heart Association, American College of Cardiology Society for Cardiovascular Angiography and Interventions, American College of Surgeons, and American Dental Association, with representation for the American College of Physicians. Circulation 115(6): 813-818.
22. DeCaterina R, Lanza M, Manca G, Strata GB, Maffei S, et al. (1994) Bleeding time and bleeding: an analysis of the relationship of the bleeding time test with parameters of surgical bleeding. Blood 84(10): 3363-3370.

23. Ferraris VA, Swanson E (1983) Aspirin usage and perioperative blood loss in patients undergoing unexpected operations. Surg Gynecol Obstet 156(4): 439-442.

24. Oates T, Beirne R, Ellingsen J (2008) Antibiotic prophylaxis for routine implant placement. Int J Oral Maxillofac Implants 23: 3.

25. Mazzocchi A, Passi L, Moretti R (2007) Retrospective analysis of 736 implants inserted without antibiotic therapy. Oral Maxillofac Surg 65(11): 2321-2323.

26. Zarb GA, Schmitt A (1994) Osseointegration for elderly patients: the toronto study. Prosthet Dent 72(5): 559-568.

27. Roynesdal AK, Amundrud B, Hannaes HR (2001) A comparative clinical investigation of 2 early loaded ITI dental implants supporting an over denture in the mandible. Int J Oral Maxillofac Implants 16(2): 246-251.

28. Mokdad AH, Bowman BA, Ford ED, Vinicor F, Marks JS, et al. (2001) The continuing epidemics of obesity and diabetes in the United States. JAMA 286(10): 1195-1200.

29. Hanlon JT, Schmader KE, Ruby CM, Weinberger M (2001) Suboptimal prescribing in older inpatients and out patients. J Am Geriatr Soc 49(2): 200-209.

30. Hajjar ER, Cafiero AC, Hanlon JT (2007) Polypharmacy in elderly patients. Am J Geriatr Pharmacother 5(4): 345-351.

31. Mealey BL, Ocampo G (2007) Diabetes mellitus and periodontal disease. Periodontol 2000 44: 127-253.

32. Mealey BL, Oates TW (2006) Diabetes mellitus and periodontal diseases. J Periodontol 77(8): 1289-1303.

33. Nevins ML, Karimbux NY, Weber HP, Giannobile WV, Fiorellini JP (1998) Wound healing around endosseous implants in experimental diabetes. Int J Oral Maxillofac Implants 13(5): 620-629.

34. Iyama S, Takeshita F, Ayukawa Y, Kido MA, Suetsugu T, et al. (1997) A study of the regional distribution of bone formed around hydroxylapatite implants in the tibiae of streptozotocin-induced diabetic rats using multiple fluorescent labelling and confocal laser scanning microscopy. Periodontol 68(12): 1169-1175.

35. Casap N, Nimri S, Ziv E, Sela J, Samuni Y (2008) Type 2 diabetes has minimal effect on osseointegration of titanium implants in Psammomys obesus. Clin Oral Implant Res 19(5): 458-464.

36. Kwon PT, Rahman SS, Kim DM, Kopman JA, Karimbux NY, et al. (2005) Maintenance of osseointegration utilizing insulin therapy in a diabetic rat model. J Periodontol 76(4): 621-626.

37. Klokkevold PR, Han TJ (2007) How do smoking, diabetes and periodontitis affect outcomes of implant treatment? Int J Oral Maxillofac Implants 22(Suppl): 173-202

38. Olson JW, Shernoff AF, Tarlow JL, Colwell JA, Scheetz JP, et al. (2000) Dental endosseous implant assessments in a type 2 diabetic population: a prospective study. Int J Oral Maxillofac Implants 15(6): 811-818.

39. Peled M, Ardekian L, Tagger GN, Gutmacher Z, Machtei EE (2003) Dental implants in patients with type 2 diabetes mellitus: a clinical study. Implant Dent 12(2): 116-122.

40. Behneke A, Behneke N, d'Hoedt B (2002) A 5-year longitudinal study of the clinical effectiveness of ITI solid screw implants in the treatment of mandibular edentulism. Int Oral Maxillofac Implants 17(6): 799-810.

41. Meijer HJ, Batenburg RH, Arghoebar GM, Vissink A (2004) Mandibular over dentures supported by two Branemark, IMZ or ITI implants: a 5-year prospective study. Clin Periodontol 31(7): 522-526. 
42. Morris HF, Ochi S, Winkler S (2000) Implant survival in patients with type 2 diabetes: Placement to 36 months. Ann Periodontol 5(1): 157165.

43. Fiorellini JP, Chen PK, Nevins M, Nevins ML (2000) A retrospective study of dental implants in diabetic patients. Int J Periodontics Restorative Dent 20(4): 366-373.

44. American Diabetes Association (2008) Standards of medical care in diabetes-2008. Diabetes Care 31(Suppl 1): S12-S54.

45. Diabetes Control and Complications Trial Research Group (1993) The effect of intensive treatment of diabetes on the development and progression of long-term complications in insulin-dependent diabetes mellitus. N Engl J Med 329: 977-986.

46. UK Prospective Diabetes Study (UKPDS) Group (1998) Intensive blood-glucose control with sulphonylureas or insulin compared with conventional treatment and risk of complication in patients with type 2 diabetes (UKPDS 33). Lancet 352(9131): 837-853.

47. Dowell S, Oates TW, Robinson M (2007) Implant success in people with type 2 diabetes mellitus with varying glycemic control: a pilot study. Am Dent Assoc 138(3): 355-361.

48. Johnson GK, Guthmiller JM (2007) The impact of cigarette smoking on periodontal disease and treatment. Periodontol 2000 44: 178-194.

49. Bain CA, Moy PK (1993) The association between the failure of dental implants and cigarette smoking. Int J Oral Maxillofac Implants 8(6): 609615.

50. Lambert PM, Morris HF, Ochi S (2000) The influence of smoking on 3-year clinical success of osseointegrated dental implants. Ann Periodontol 5(1): 79-89.

51. Hinode D, Tanabe S, Yokoyama M, Fujisawa K, Yamauchi E, et al. (2006) Influence of smoking on osseointegrated implant failure: a metaanalysis. Clin Oral Implants Res 17(4): 473-478.

52. Strietzel FP, Reichart PA, Kale A, Kulkarni M, Wegner B, et al. (2007) Smoking interferes with the prognosis of dental implant treatment: a systematic review and meta-analysis. Clin Periodontol 34(6): 523-544.

53. Klokkevold PR, Han TJ (2007) How do smoking, diabetes and periodontitis affect outcomes of implant treatment? Int J Oral Maxillofac Implants 22(Suppl): 173-198.

54. Buser D, Ingimarsson S, Dula K, Lussi A, Hirt HP, et al. (2002) Longterm stability of osseointegrated implants inaugmented bone: a 5-year prospective study in partially edentulous patients. Int Periodontics Restorative Dent 22(2): 109-117.

55. Wallace SS, Froum SJ (2003) Effect of maxillary sinus augmentation on the survival of endosseous dental implants. A systematic review. Ann Periodontol 8(1): 328-343.

56. Esposito M, Grusovin MG, Coulthard P, Worthington HV (2006) The efficacy of various bone augmentation procedures for dental implants: a Cochrane systematic review of randomized controlled clinical trials. Int J Oral Maxillofac Implants 21(5): 696-710.

57. Bain CA, Weng D, Meltzer A, Kohles SS, Stach RM (2002) A meta-analysis evaluating the risk for implant failure in patients who smoke. Compend Contin Educ Dent 23(8): 695-704.
58. Kumar A, Jaffin RA, Berman C (2002) The effect of smoking on achieving osseointegration of surface-modified implants: a clinical report. Int Oral Maxillofac Implants 17(6): 816-819.

59. Weyant RJ (1994) Characteristics associated with the loss and periimplant tissue health of endosseous dental implants. Int J Oral Maxillofac Implants 9(1): 95-102.

60. Yin JT, Dobkin JF, Grbic JT (2007) Epidemiology, pathogenesis, and management of human immunodeficiency virus infection in patients with periodontal disease. Periodontol 2000 44: 55-81.

61. Achong RM, Shetty K, Arribas A, Block MS (2006) Implants in HIVpositive patients: 3 case reports. Oral Maxillofac Surg 64(8): 1199-1203.

62. Stevenson GC, Riano PC, Moretti AJ, Nichols CM, Engelmeier RL, et al. (2007) Short-term success of osseointegrated dental implants in HIVpositive individuals: a prospective study. Contemp Dent Pract 8(1): 1-10.

63. Streitzel FP, Rothe S, Reichart PA, Schmidt WAM (2006) Implantprosthetic treatment in HIV-infected patients receiving highly active antiretroviral therapy: report of cases. Int Oral Maxillofac Implants 21(6): 951-956

64. Miller CS, Egan RM, Falace DA, Rayens MK, Moore CR (1999) Prevalence of infective endocarditis in patients with systemic lupus erythematosus. J Am Dent Assoc 130(3): 387-392.

65. Nelson K, Heberer S, Glatzer C (2007) Survival analysis and clinical evaluation of implant-retained prostheses in oral cancer resection patients over a mean follow-up period of 10 years. J Prosthet Dent 98(5): 405-410.

66. Kovacs AF (2000) Clinical analysis of implant losses in oral tumor and defect patients. Clin Oral Implants Res 11(5): 494-504.

67. Kovacs AF (2001) Influence of chemotherapy on endosteal implants survival and success in oral cancer patients. Int J Oral Maxillofac Surg 30(2): 144-147.

68. Barasch A, Coke JM (2007) Cancer therapeutics: an update on its effects on oral health. Periodontol 2000 44: 44-54.

69. Colella G, Cannavale R, Pentenero M, Gandolpho S (2007) Oral implants in radiated patients: a systematic review. Int Oral Maxillofac Implants 22(4): 616-622.

70. Granstrom G (2005) Osseointegration in irradiated cancer patients: an analysis with respect to implant failures. Oral Maxillofac Surg 63(5): 579-585.

71. Yerit KC, Posch M, Seemann M, Hainich S, Dortbudak O, et al. (2006) Implant survival in mandibles of irradiated oral cancer patients. Clin Oral Implants Res 17(3): 337-344.

72. Schoen PJ, Raghoebar GM, Bouma J, Reintsema H, Vissink A, et al. (2007) Rehabilitation of oral function in head and neck cancer patients after radiotherapy with implant-retained dentures: effects of hyperbaric oxygen therapy. Oral Oncol 43(4): 379-388.

73. Esposito M, Irsch JM, Lekholm U, Thomsen P (1998) Biological factors contributing to failures of osseointegrated oral implants. 1. Success criteria and epidemiology. Eur J Oral Sci 106: 527-551. 


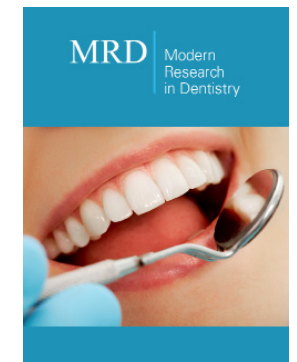

\section{Modern Research in Dentistry}

\section{Benefits of Publishing with us}

- High-level peer review and editorial services

- Freely accessible online immediately upon publication

- Authors retain the copyright to their work

- Licensing it under a Creative Commons license

- Visibility through different online platforms 